\title{
A CASE STUDY OF GEOTHERMAL RESOURCES USE FOR THE INNOVATIVE AQUACULTURE FROM PERSPECTIVE OF SYNTROPIC DEVELOPMENT CONCEPT
}

\author{
LESZEK ŚWIĄTEK \\ West-Pomeranian University of Technology in Szczecin, Poland
}

\begin{abstract}
Geothermal energy is developing with high progress to provide clean energy production standards at a world-wide scale. These projects are characterized with high risk level associated with drilling methods, resource existence, uncertain heat water temperature and its chemistry. The risk mitigation scenarios are crucial to avoid investment failure. Presented paper is a case study of geothermal investment in Trzęsacz, located in the Baltic coastline in Poland, where predicted heat water $\left(38^{\circ} \mathrm{C}\right)$ was planned to be used for leisure, swimming and balneological purposes. The final effect of test drilling was disruptive. Thermal water has temperature $27^{\circ} \mathrm{C}$ and is not enough to fulfill needs of planned water park facilities and hot springs recreational proposals. The concept had to be revised. The amount of wasted water and embodied energy were recognized as a high entropy problem. In the spirit of syntropic development model, an idea to consume unwanted geothermal water and to treat it as useful local resource for aquaculture purposes was taken into consideration. That way the Jurassic Salmon Farm realization in Janowo in 2015, the first in the world salmon fishery based on geothermal resources, became an inspiration for future fishery deliberation, the fastest growing food sector globally. The Farm was realized $5 \mathrm{~km}$ from operating geothermal well, supported with EU funds and research programme led by West - Pomeranian University of Technology in Szczecin. The greenfield investment powered by renewable energy, based on biosafety and industrial ecology rules is an example of the 21 st century bioculture. This one moved to urban areas may comply with broad sense to the city aquaculture, aquaponics or urban agriculture, with improvement of the risk reduction strategy in geothermal energy investments. This is the potential to be used by local communities, which can favor synergy effect on the way to regenerative design and syntropic development model.

Keywords: geothermal energy development, syntropy, sustainable aquaculture, regenerative design, risk mitigation.
\end{abstract}

\section{INTRODUCTION}

In the era of the fourth industrial revolution, the dominant part of the human population is concentrated in urbanized regions. Increasing cities are often conducive to concentration of economic capital, enable development and transfer of knowledge while struggling with the consequences of loss of natural capital. Both large metropolises as well as small and medium towns are affected by environmental problems, degenerative diseases of urban areas, imposing a negative ecological footprint in the natural environment both at the regional and global level. In order to minimize anthropopressure on the environment, discussions on healing the city's metabolism are underway, looking for sustainable development alternatives in the form of positive development, low-entropy city or syntropic development models. Newman et al. [1] reports 'The road to resilient cities requires finding ways of relating urban metabolism to practical, daily urban planning. We suggest that it can be done by examining urban metabolism in each of the urban fabrics. How can the materials and resources they use be regenerated and foster a mutually beneficial relationships between urban areas and the planet?' 


\subsection{Characteristic of the syntropic development model}

Promoting Nature-Based Solutions Pelorosso et al. [2] noticed: 'Entropy is a measure of the disorder, or waste of the city, and as such can be considered an indicator of the diversified impacts of the urban development on the biosphere. The entropy release of a city today is excessive because it overcomes Earth`s natural capacity of regeneration and threatens to destabilise the urban (human) civilization itself, which is causing it.' The counter force to increasing entropy is syntropy described by Hungarian biochemist Szent-Györgyi, Nobel Prize winner who postulates the existence of a force that causes living things to reach 'higher and higher levels of organization, order, and dynamic harmony' [3]. This way all living things can be characterized with the tendency to decrease entropy - in contrast to the tendency for inanimate matter to increase entropy (total equilibrium or total diffusion, producing a maximum of entropy and a minimum of free energy) [4]. Buckminster Fuller's student Baldwin [5] underlines: 'Bucky said that biology balanced entropy. Humans were the most powerful (known) antientropic forces of all, because we accumulate and purvey knowledge, adding local order to Universe in the same way that a plant synthesises air, sunlight, and soil nutrients into botanical life. Because anti-entropy is a double negative, Bucky called it 'syntropy'. Our purpose and duty as humans is to be syntropic'. The syntropic development model convergent to the positive development [6] is employing the recirculation economy, regenerative design and clean renewable energy production.

\subsection{The syntropic approach to geothermal energy investment}

Geothermal energy as one of renewable resources is developing with high progress to provide clean energy production standards world-wide. These projects are characterized with high risk level associated with drilling methods, resource existence, uncertain heat water temperature and its chemistry. Entropy as well as syntropy also applies to energy or investment economy. The risk mitigation scenarios are crucial to avoid investment failure characterized with high entropy level. The risk strategies should be a part of any urban development plans, feasibility studies and architectural design processes, where decreasing entropy level mechanisms should be supplemented with syntropic development models too. Geothermal projects are focused on energy aspects mainly, where the water is a medium that works as a heat supplier. Water is the environment of life. It's the one that cleanses, revives and regenerates. Water taken from geothermal projects can play a role as a vital resource for productive green areas restoration, municipal forest plantations or cultivation of urban agriculture and aquaculture supported with renewable energy in frames of urban water management. Together with the migration of people from rural areas to growing cities, the ideas of transferring agricultural production to densely populated urban areas are emerging. Design and cooperation in the implementation of the Jurassic Salmon farm in Janowo (West Pomeranian Voivodship in Poland), the world's first closed salmon farm based on geothermal sources and autonomous water recirculation systems (RAS, Recirculation Aquaculture System) became an inspiration to consider the future of aquaculture and geothermal projects [7]. This type of controlled fish farming is recognized as the fastest growing food production sector on a global scale, based on innovative technologies supported by extensive research programs and the interest of international investment capital.

\subsection{Aquaculture, energy and urban food production}

Since 2000, the increase in aquaculture production has been recorded at $7 \%$ per annum on a global scale. Currently, 50\% of world fish and seafood consumption comes from 
controlled farms [8]. At the same time, on the example of a noble fish species, the dynamics of salmon consumption is characterized by a rapid growth on a global scale. Its consumption in 2015 was 1.2 million tons, while in 2050 it is to rise to the level of 5 million tons [9]. Within the European Union, it is estimated that $48 \%$ of natural fish stocks are affected by the overfishing and loss of the ability to regenerate and restore vital herds [10]. For this reason, the EU's Common Fisheries Policy assumes the promotion of environmentally-friendly aquaculture models. Compared to traditional fish farms in open water areas (e.g. in the Norwegian fjords), land based farms with RAS radically support the saving of water resources, eliminate the process of pollution and eutrophication - especially as sensitive marine areas as the semi-enclosed Baltic Sea basin. Fish farms planned under one roof provide stability and control of the breeding environment, maintain a high level of biosafety, reducing the risk of diseases, the appearance of parasites or predators (e.g. cormorants) depleting the size of the breeding stock. RAS technologies guarantee a constant level of production (comparable in quantity and quality in a weekly cycle throughout the year), eliminate the risk of fish escapement or theft occurring commonly in open ponds. The future of RAS is in autonomous large scale farms, based on integrated processing, local fodder plants, development of aquaponics and hydroponic gardening [11]. This leads to the creation of eco-friendly agro-machines - production and logistics systems such as environmental hubs that exploit the synergy effect, principles of integrated and sustainable supply chain, circular waste utilization and cascade energy consumption in order to strengthen the environmental efficiency of planned investments. Hence the urban locations of integrated fish farms and urban agriculture combined with the processes of revitalization of post-industrial areas (brownfield and greyfield investments) become an interesting research issue, especially when urban farms are often associated with a bottom-up social movement promoting the production of fresh local food and a network distribution system. Ecological technologies used in Jurassic Salmon can be a good example and inspiration for the implementation of such projects in urban areas with diverse functional systems, heterogeneous social structure or dense network infrastructure.

\section{JURASSIC SALMON FARM IN JANOWO - A CASE STUDY}

Initiated in 2010 by local investors, the project was implemented on the basis of EU funds under the Operational Programme 'Sustainable development of fisheries and coastal fishing areas 2007-2013' action 3.5 Pilot projects and on the basis of the research program 'Using geothermal saline water for fish farming and breeding'. Run by the West Pomeranian University of Technology in Szczecin under the supervision of professor Jacek Sadowski, with the procedural support of the municipalities of Karnice and Rewal. The analyzed case study is a greenfield investment, powered by renewable energy. A farm operating on the basis of strict biosafety regulations, industrial ecology, resource efficiency and responsible production was designed. It is the only breeding in the world in which salmon develops and grows in a very clean and microbiologically safe geothermal water from the Lower Jurassic period, and the third plant that produces from roe to an adult fishes under one roof [9].

\subsection{The genesis of the project - the issue of ecological effectiveness}

The plans of the investor associated with Trzęsacz (a former fishing village with the characteristic ruins of a Gothic church on the cliff of the central Baltic coast in the Rewal commune) assumed the implementation of a year-round holiday center in the historic palace complex. The revitalization of the seventeenth-century palace for the hotel function to be preceded by 
the implementation of the congress center with a complex of recreational pools on the outskirts of the palace park. The attraction of the entertainment part was to be an aqua park equipped with internal and external thermal pools with a total water surface area of approximately 1500 sq. m. An analogous water park powered by geothermal sources (water temperature about $36^{\circ} \mathrm{C}$ ) operates in the German border town Ahlbeck $-3 \mathrm{~km}$ from Świnoujście. In the vicinity of the palace complex, the investor took a geothermal water intake Trzęsacz GT-1 with a hole depth of 1224.5 m.p.p. and with a flow rate of $180 \mathrm{~m}^{3} / \mathrm{h}$ and a working temperature of $25.4^{\circ} \mathrm{C}$ [12]. The project was co-financed from The National Fund for Environmental Protection (NFEP) subsidies, however, the obtained thermal parameters of geothermal water proved to be lower than assumed, although the chlorine-sodium saltwater obtained from the aquifer of Lower Jurassic has a mineralization of $13.5 \mathrm{~g} / \mathrm{l}$ and have positive properties for balneological needs. However, the relatively low temperature of geothermal water did not guarantee the economic viability of planned, warm thermal pools, which should be additionally heated with the use of other energy sources. The local authorities of Lidzbark Warmiński town landed themselves in a similar situation, where the temperature of water obtained from the geothermal well was $21^{\circ} \mathrm{C}$, which did not stop the implementation of thermal baths and the heating of swimming pools in the aqua park. The investor in Trzęsacz revised the investment plans and made a decision on other use of geothermal water. Heat recovery for the needs of the heating installation in the palace building and pumping geothermal water for the investor's agricultural plots located in Janowo (Karnice commune), distant $5 \mathrm{~km}$ from the water intake, were initially planned. The already partly chilled geothermal water is used for technological processes in fish farming. The investment was based on the innovative Danish aquaculture technology for closed land farms with water recirculation systems (RAS). As a result, geothermal water is used in an effective way not only for the purpose of obtaining thermal energy but also for feeding in a controlled environment of Atlantic salmon farming ecosystems.

\subsection{Industry 4.0 and Nature 4.0 ecosystems on the example of the Jurassic Salmon farm}

The central facility on the premises of the Jurassic Salmon Breeding Center established in 2013 is the modern, compact production building of the fish farm with a usable area of approx. 9,000 sq. m. The one-storey hall includes a number of technical rooms, including geothermal and sweet water treatment and iron removal stations, filter stations, sewage treatment plants, denitrification systems and sludge treatment [13]. The main building is occupied by separate rooms with different breeding tanks sizes for fish farms (Fig. 1). The production cycle lasts 20-22 months, starting from the spawning phase of eggs (imported by air from Norway or Iceland) through the growth of fry, smolt grow up to the rearing phase of adults reaching a commercial weight of $5-6 \mathrm{~kg}$.

The building operates as a kind of a large, integrated device - a form of research equipment monitoring a specific environment of Atlantic salmon farming. The artificial ecosystems, type Nature 4.0, [14] were implemented, which reflect typical life cycles of fish, with five closed water circuits in two environments: cold fresh water and warm geothermal water from the 150-year-old Jury period. The breeding takes place in a hall only lighted with artificial light of variable intensity, including the backlighting of the interior of breeding tanks with colored LED light. The nozzles placed in cylindrical tanks regulate the velocity and direction of the water stream, in which the salmons swim upstream (Fig. 2). The investment area was equipped with an extended Building Management System (BMS) controlling many technological processes and environment, monitoring the signals of sensors testing the temperature 


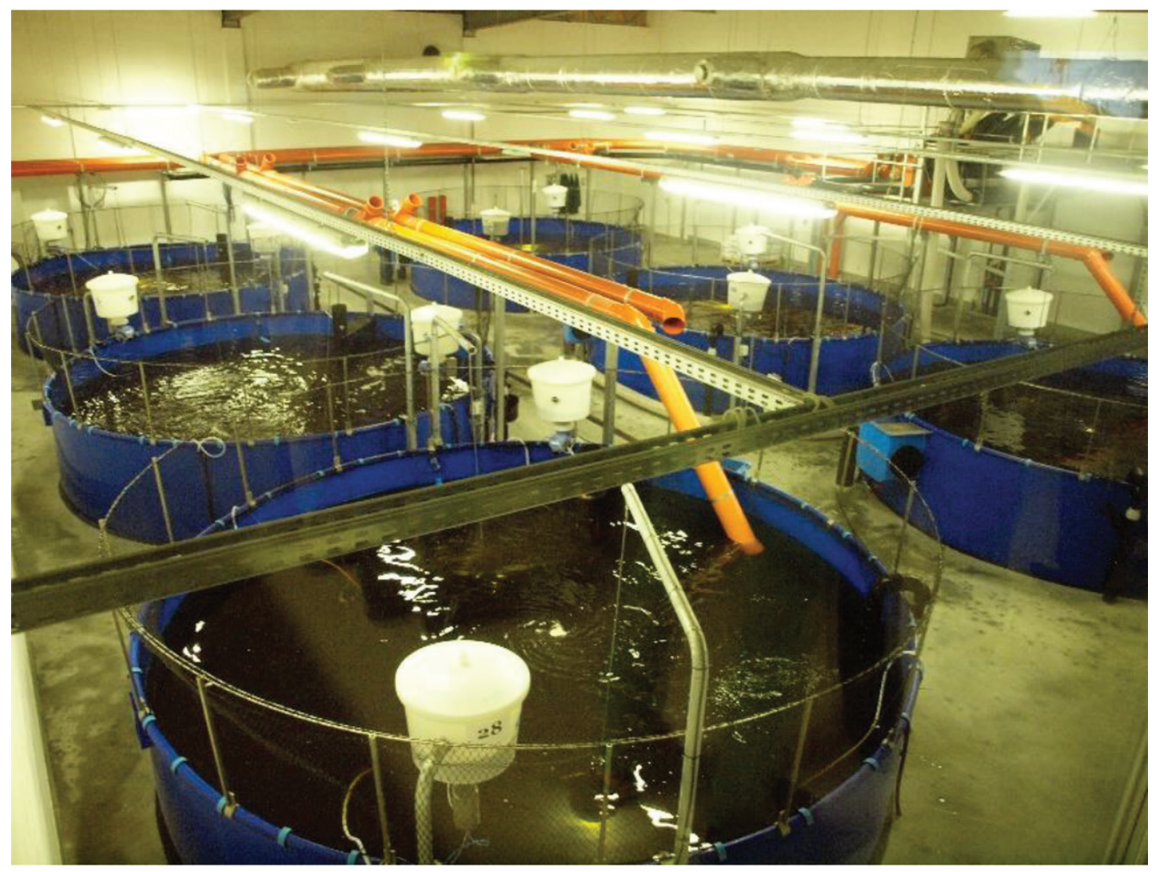

Figure 1: Salmon breeding tanks (5m diameter) - post-smolt cycle phase on the Jurassic Salmon farm. Picture of the author.

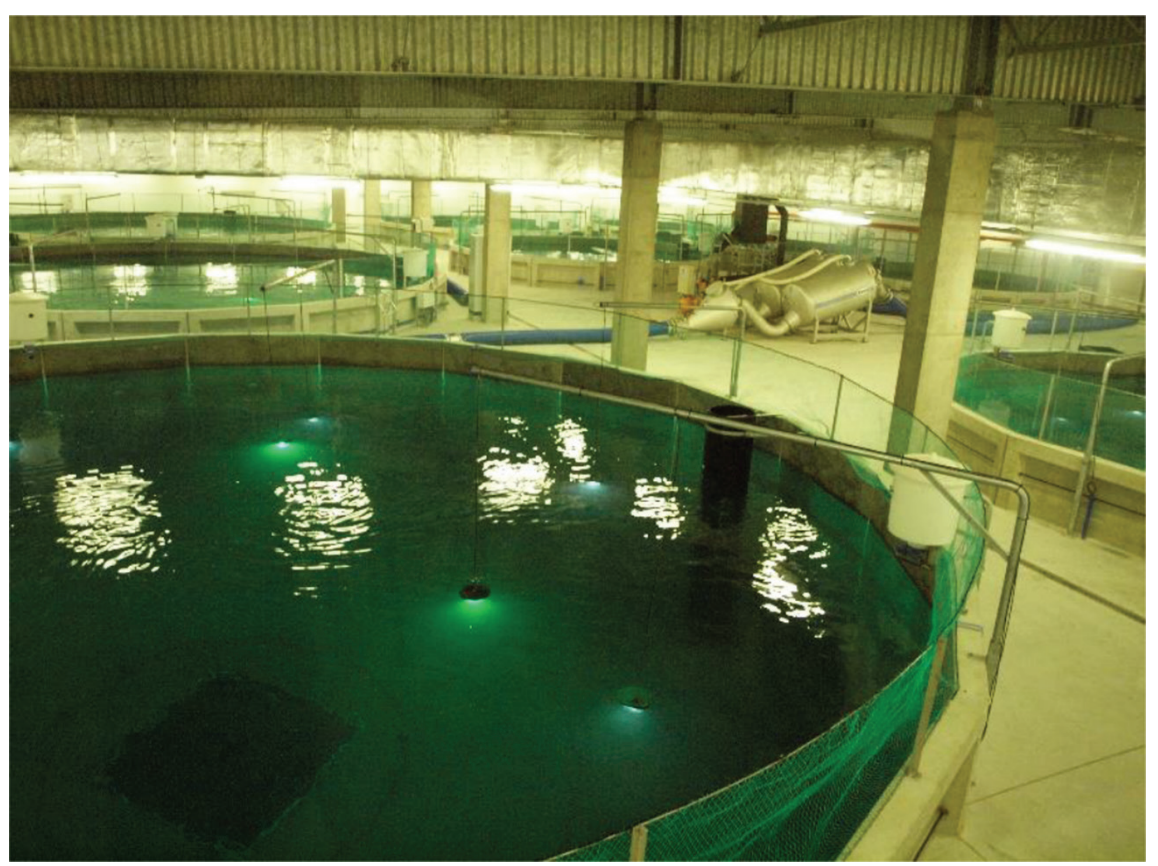

Figure 2: Salmon breeding tanks with a diameter of $12 \mathrm{~m}$ and a depth of up to $6 \mathrm{~m}$ - grow up phase on the Jurassic Salmon farm. Picture of the author. 
of water and production rooms, oxygen dosing, stability of the biological deposit, or emergency states of particular circuits [13]. For the needs of the research program, the quality parameters of the water and its physicochemical parameters were analyzed, such as: $\mathrm{pH}$ level, ammonia, nitrites, nitrates, CO2, BZT5, CHZTcr, total phosphate and phosphorus content, within the tolerance range for fish with the highest environmental requirements [15]. Many automation, surveillance or monitoring solutions have been adapted to mobile devices with emergency notification applications, staff on duty around the clock. The technological project and related infrastructure were implemented based on the BIM system and a virtual spatial model made available in a virtual cloud. This makes it easier to manage a building at a distance, speeds up servicing and maintenance, which is a characteristic feature of the Industry 4.0 investment (Industrie 4.0).

Industry 4.0 is a collective term meaning the integration of intelligent machines, systems and introducing changes in production processes aimed at increasing production efficiency and introducing the possibility of flexible product changes. Industry 4.0 is characterized by the convergence of the physical and virtual world (cyberspace) in the form of cyber-physical systems (CPS), concerns not only technology, but also new ways of working and the role of people in industry. Industrie 4.0 (Germany) is a platform connecting representatives from various areas, including industry, policy, business and R\&D aimed at standardization and increasing the security of network systems, creating legal frameworks, promoting research and innovation [16].

\section{THE MODEL OF INTEGRATION OF CAPITAL AND KNOWLEDGE - CREATING INNOVATIVE SOLUTIONS}

The realized pilot building of the Atlantic salmon farm Jurassic Salmon in Janowo received co-financing from the EU funds at the level of 5,8 million euro, with a total investment cost of about 10,4 million euro [9]. The investor's own contribution covered the implementation of a vast infrastructure providing the necessary utilities to the construction site. Infrastructural activities took place in the area of two neighboring communes: Rewal and Karnice. Local government authorities supported the investment especially in the planning and design phase. The Rewal commune has supported and streamlined the procedures for the implementation of the geothermal well and the water intake. One of the objectives was to distribute thermal energy from renewable sources to nearby recreation centers with positive operational parameters of the intake. The procedures enabling the execution of line investments in the commune road belt, in the area of the geothermal supply and return water infrastructure as well as the transmission of fresh drinking water from private wells of the investor were efficiently performed. Employees of the Commune Office were involved in constructively solving problems related to environmental procedures (e.g. water law) and in mediating in neighborly disputes of ownership and formal-legal interpretations of regulations. The rural municipality of Karnice favored the investment by supporting work on the local land development plan for agro-park in the area of approximately 13 hectares in the region of Janowo. The commune agreed to the extension of the municipal water supply network towards the village of Janowo, in order to supply the farm with fresh water in the initial phase of the investment. In cooperation with the district authorities in Gryfice, permission was granted to reconstruct the local road in order to ensure appropriate technical parameters of access to the farm and ensure continuity of supplies and cyclical collection of mature fish. The completed research program confirmed the correct functioning of the built-in pilot plant for fish farming. The geothermal waters used in Jurassic Salmon intensified fish production by shortening the 
breeding cycle and increasing their resistance to diseases, which reduced mortality rates in the herd scale. During the investment, apart from specialists from Poland, the project involved experts from Denmark, Iceland, Norway, France, Chile and Indonesia. At present, 21 people found employment in the Jurassic Salmon Breeding Center in Janowo. Weekly fish production has stabilized at the level of 12-15 tons, with a production capacity of up to 20 tons per week. The company was the first in the country to obtain the international certificate of The Aquaculture Stewardship Council (ACS) for sustainable fish farming [9].

The activities of Jurassic Salmon and scientists from West Pomeranian University of Technology of Szczecin during the implementation and commissioning of a modern fish farm in Janowo and the results obtained contribute to the development of aquaculture both on a national and international scale. The idea of controlled breeding is an example of the bioculture of the 21st century, which transferred to urbanized areas can be part of widely understood city aquaculture, aquaponics or urban agriculture. This will result in a different perception of Nature by urban residents in the near future than in today and foster the creation of an innovative economy.

\section{REMARKS ON THE IMPLEMENTATION}

The implementation of a technologically complicated facility and a complex research project in the unchallenged time frame, resulting from EU funding dates and procedures, imposes rigorous discipline in making investment decisions. The short schedule of design work, preparation and construction of the farm together with the necessary infrastructure did not allow for prolonging administrative procedures, entangling in legal formal disputes with unfavorable neighbors or stoppages during the execution of construction works. In the domestic conditions, it seems that carrying out such a difficult investment in a short time is easier in the open rural space than in densely populated, conflictogenic urban areas. Local authorities of small municipalities strive for such projects (environmentally friendly, generating new jobs), create systems of incentives and procedural facilitation of organizational support during the investment implementation period. However, there is a doubt about the ecological effectiveness of such activities. Is there no effect of some capital dissipation and loss of potential synergy of investments implemented in the greenfield formula compared to urbanized areas (with existing extensive installation and road infrastructure) where brownfield or greyfield investments can be implemented? In rural areas it is more difficult to implement new access roads, it is more difficult to maintain them during the winter period (snow clearing classes), it becomes cumbersome to provide rational terrain with a large disperse of recipients. Due to the distance of the farm there will be difficult access of service teams and experts in comparison to urban locations (availability of airports, accommodation base, universities and research institutes). The phase of investment preparation and design, with extensive administrative and environmental procedures and at the same time with short and strict deadlines for obtaining EU funds requires quick and efficient decision-making by both the investor and the project team. Transferring the design process to the virtual cloud, current (on-line) reporting of the process of introducing functional, technological and installation changes as well as operating on the 3D model of the planned investment significantly accelerated the decision-making process and the implementation of construction works. The anticipated stage of the investment made it possible to conditionally collect a previously made salmon hatchery and start breeding with the rigors of biosafety, practically during the construction period. Such activity enabled the launching of the breeding cycle and the early start of scientific and research work, as part of the dissemination of Industry 4.0 formulas. 

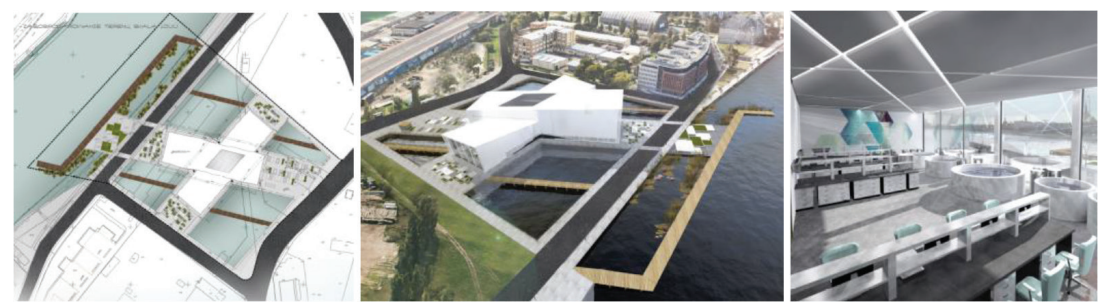

Figure 3: Project of the Research Centre - Aquaculture Lab located in the postindustrial city fabric of Szczecin on the Odra River bank. (Muszalska A., Świątek L. ZUT Szczecin, 2018).

The Jurassic Salmon farm has confirmed the wider use of geothermal water than just for energy needs. After the tests, the adapted and treated Jurassic water turned out to be an excellent environment for salmon farming. In comparison with surface water resources, used at traditional farms, geothermal water, due to the hermeticity of the deep underground deposit, is free from chemical pollution or dangerous to fish parasites. RAS systems used on the farm have become a kind of filter for mineralized geothermal waters when they are reintroduced into the environment. After recovering thermal energy and mixing saline thermal water with fresh water in order to create a proper living environment for adolescent salmon, after re-purification (through mechanical filters and biological deposit) water from the farm returns to the environment through a drainage channel system, feeding the sweet and salt lake of Liwia Łuża. The presented solution can be a model example of the cascade use of geothermal energy to reduce energy losses, but also the practical use of thermal water resources for the needs of fish farming. In this model of water use, the costly second borehole that injects the cooled geothermal water back to the ground is eliminated. The described implementation is also a proof that the lack of positive temperature parameters of geothermal water obtained after the actual drilling has not necessarily led to discontinuation of further investment activities. Investor's determination, with the support of the scientific community and local self-government authorities, set the path for conducting an innovative investment in the $21 \mathrm{st}$ century food production sector, showing the method of reducing the level of risk in geothermal drilling and the possibility of using waters with low potential of thermal energy as an element of syntropic development model. Association of contemporary aquaculture with geothermal water acquisition opens the perspective of implementation of this type of investment in urbanized areas, equipped with a dense network of infrastructure, access to research centers, logistics centers and processing plants based on cascade energy consumption and industrial ecology formulas (Fig. 3).

\section{CONCLUSIONS}

The case described above can be characterized by a sentence: how to turn an investment failure into a success. The Jurassic Salmon Farm with its innovative aquaculture complex systems appears to be operating well, and plans are to expand fish processing plant to increase high quality food production. The compact fish farm, closed under one roof, is an example of an effective solution to the problem of a low enthalpy geothermal source and direct use of thermal water for fish breeding. The presented measure reduces the entropy level of geothermal investment, at the same time increasing its level of syntropy. Such a solution eliminates the need for a costly and troublesome reinjection well as a result of the process of thermal 
fluid treatment for fish farming and its environmentally neutral discharge into natural water reservoirs. The use of geothermal resource maximization was achieved. A compact farm can be used as a ready-made, repeatable component in a cascading geothermal energy utilization model. This type of investment requires large capital expenditure. However, it should be pointed out that the initial capital of the Jurassic Salmon farm was subsidized by European Union funds at the level of $75 \%$, due to the pilot and innovative project. The peripheral location and ecological footprint of the greenfield investment, for which new infrastructure with extensive use has been implemented, raise some doubts. Both the implementation of water wise design principles (e.g. water footprint analysis) of land-based closed fish farms as well as the possibility to adapt aquaculture with RAS systems to the built environment requires further research. Have migrations of intensive agricultural production into urbanized areas in the 21 st century right to exist, or are economically justified, it is the issue unlikely to be quickly resolved in the near future. But anyway the effectiveness of closed fish farm investment should be greater in urban areas, where intensive infrastructure, various media networks and users higher density exist. Geothermal energy effectiveness, current technological and logistics solutions enable the development of urban agriculture, with particular emphasis on aquaculture and aquaponics. Undoubtedly, this is a vast area of potential multidisciplinary research, planning or economic analysis. The city farms may create the effect of technological symbiosis inscribed in the hybrid cascade model of using geothermal resources (mix of thermal energy and thermal fluids) in greyfield or brownfield eco-industrial parks to generate the synergy effect. This will have an impact on the implementation of urban agriculture and building a positive development model towards a new syntropic city. However, the dissemination of urban agriculture intensified with renewable energy sources will demonstrate the bioculture development of city dwellers, the scale of social ecological intelligence and the type of the relationship with Nature, including the sublime Nature 4.0. This is potential for use by the local community, city authorities, academia and business representatives that can promote the synergy effect on the way to regenerative planning and syntropic development model.

\section{REFERENCES}

[1] Book: Newman, P., Beatley, T., Boyer, H., Resilient Cities, Second Edition: Overcoming Fossil Fuel Dependence, Island Press; Second Edition, Washington, p. 157, 2017.

[2] Book: Pelorosso, R., Gobattoni, F., Leone, A., Reducing Urban Entropy Employing Nature-Based Solutions: The Case of Urban Storm Water Management in: Papa, R., Fistola, R., Gargiulo, C. (eds.) Smart Planning: Sustainability and Mobility in the Age of Change, Springer International Publishing AG, p. 37, 2018.

[3] Journal article: Vargiu, J., Editor of Synthesis 1 (Introduction to article by Szent-Györgyi). Synthesis 1, 1(1), p. 14, 1977.

[4] Book: Scaruffi, P., Thinking about Thought: A Primer on the New Science of Mind, Writers Club Press, New York, p. 280, 2003.

[5] Book: Baldwin, J., Bucky Works: Buckminster Fuller's Ideas Today, John Wiley \& Sons, Hoboken, pp.226-227, 1996.

[6] Book: Birkeland, J., Positive Development: From Vicious Circles to Virtuous Cycles through Built Environment Design, Earthscan, London, 2008.

[7] Journal article: Świątek, L., Akwakultura Miejska - model integracji kapitału i wiedzy w przestrzeni komunalnej - Natura 4.0. The City Aquaculture - capital and knowledge integration model in municipal development - Nature 4.0., PUA 
Przestrzeń Urbanistyka Architektura, Vol. 1, Wydawnictwo PK, Kraków, 2017. doi:10.4467/00000000PUA.17.019.7137

[8] Book: Bregnballe J. A., Guide to Recirculation Aquaculture. An introduction to the new environmentally friendly and highly productive closed fish farming systems, Food and Agriculture Organization of the United Nations (FAO), EUROFISH International Organisation; 2015.

[9] Online sources: Jurassic Salmon sp. z o.o. Online, http://jurassicsalmon.pl. Accessed on: 12 Jul. 2016.

[10] Book: Neudörfer F. Sustainable Fish Aquaculture. in: Schultz-Zehden, A., Matczak, M., (eds.) Submariner Compendium. An Assessment of Innovative and Sustainable Uses of Baltic Marine Resources, Maritime Institute in Gdańsk, pp. 204-230, 2012.

[11] Book: Vinci, BJ., North American Perspective on Land Based Aquaculture: Past. Present \& Future, The Conservation Fund Freshwater Institute, Shepherdstown, 2015.

[12] Online sources: Kowalski M. Land based salmons from Poland. Jurassic Salmon, Szczecin 2015, Online, http://www.ccb.se. Accessed on: 23 Jun.2016.

[13] Technical specification: Świątek, L., Description for the Building Project of the production hall in Janowo for the company Jurassic Salmon, AKCENT Pracownia Projektowa, Szczecin, 2013.

[14] Conference: Świątek, L., From Industry 4.0 to Nature 4.0 - Sustainable Infrastructure Evolution by Design. In: Charytonowicz J., Falcão C. (eds) Advances in Human Factors, Sustainable Urban Planning and Infrastructure. AHFE 2018. Advances in Intelligent Systems and Computing, vol 788. Springer, Cham, 2019. doi:10.1007/9783-319-94199-8_42

[15] Research report: Sadowski, J., The use of saline geothermal water for fish hatching and ongrowing, ZUT Szczecin, 2015.

[16] Online sources: Piątek, Z., Czym jest przemyst 4.0.? Online, http://przemysl-40.pl. Accessed on: 28 Mar.2017. 